\title{
Effects of rearing condition, gender, and sexual experience on odor preferences and urine marking in Long-Evans rats
}

\author{
RICHARD E. BROWN \\ Dalhousie University, Halifax, Nova Scotia, Canada
}

\begin{abstract}
Two experiments investigated the effects of isolation rearing on olfactory communication in rats. In Experiment 1, there were significant rearing and gender effects on the time spent investigating conspecific odors, the preferences for these odors, and the amount of urine marking over these odors by sexually naive male and female rats. Experiment 2 found significant effects of rearing condition and sexual experience on the responses of male rats to conspecific odors. In general, isolation rearing increased the time spent investigating conspecific odors, but reduced the amount of urine marking over these odors and altered the odor preference scales. These results suggest that the responses of both male and female rats to the odors of conspecifics are modified by rearing experience. The importance of learning conspecific odor signals for the development of normal social behavior is discussed.
\end{abstract}

Olfactory communication is an integral component of the social behavior of mammals such as rats. Olfactory signals provide information about the species, age, sex, individuality, and familiarity of conspecifics, as well as their social status, fear level, and state of sexual receptivity (Brown, 1979, 1985b). The inability to use olfactory information due to anosmia disrupts affiliative behavior (Thor \& Flannelly, 1977a), sexual behavior (Larsson, 1971; Wilhelmsson \& Larsson, 1973), and aggressive behavior (Alberts \& Galef, 1973; Flannelly \& Blanchard, 1982) in adult rats.

The display of appropriate social behavior depends not only on the ability to perceive conspecific olfactory signals but also on social experience. Rats lacking social experience show abnormal affiliative behavior (Latané, Nesbitt, Eckman, \& Rodin, 1972), sexual behavior (Duffy \& Hendricks, 1973; H. D. Gerall, Ward, \& A. A. Gerall, 1967; Gruendel \& Arnold, 1974; Hard \& Larsson, 1968; Hole, Einon, \& Plotkin, 1986; Thor, 1980), and aggressive behavior (Adams, 1976; Day, Seay, Hale, \& Hendricks, 1982; Hoyenga \& Lekan, 1970; Uyeno \& White, 1967; Ward \& A. A. Gerall, 1968).

Relative to the number of experiments on the effects of isolation rearing on male rats, there are very few in which the effect of rearing experience on the development of social behavior in females has been studied. Some of these have reported sex differences in the effects of iso-

This research was supported by NSERC of Canada Grant A7441. Grateful acknowledgment is given to Robin Kind and Sonya Major for their assistance in the collection of data and in the preparation of the manuscript. Reprint requests should be sent to Richard E. Brown, Department of Psychology, Dahousie University, Halifax, Nova Scotia $\mathrm{B} 3 \mathrm{H} 4 \mathrm{~J} 1$, Canada. lation rearing, whereas others have not. For example, although isolation rearing disrupts male sexual behavior, it has little effect on female sexual behavior (Duffy \& Hendricks, 1973; Hansen, 1977). Isolation rearing does, however, increase aggression, reduce affiliative behavior, and increase open field activity in female as well as male rats (Dalrymple-Alford \& Benton, 1981; Day et al., 1982).

The deficiencies in the social behavior of isolationreared rats are due, in part, to their inappropriate responses to conspecific olfactory signals (Flannelly \& Blanchard, 1982; Latané et al., 1972; Thor, 1980; Wilhelmsson \& Larsson, 1973). Inappropriate responses occur because the rats have had no opportunity to learn appropriate responses to conspecific odors. It has been hypothesized that rats learn the olfactory characteristics of their partners during social interactions and form an odor-based "social memory" that can be used in future interactions (Thor, 1979; Thor \& Holloway, 1982). If this hypothesis is correct, then isolation rearing should alter the responses of rats to the odors of conspecifics. This is examined in this paper.

Rats show two responses to the odors of conspecifics: investigation and urine marking (Birke \& Sadler, 1984; Brown, 1975, 1977; Hopp \& Timberlake, 1983). Adult social experience modifies both of these responses. Losing an aggressive interaction with a dominant male reduces the amount of scent marking done by the subordinate near the odor of the dominant male (Adams, 1976). Sexual experience increases the investigation of female odors by male rats (Brown, 1977; Stern, 1970) and establishes a preference for the odors of estrous over diestrous females (Carr, Loeb, \& Dissinger, 1965; Lydell \& Doty, 1972), but sexual experience does not alter the odor preferences or the urine-marking behavior of female rats (Brown, 1977). 
Sixty days of social isolation reduces the time investigating and the amount of urine marking over conspecific odors by adult male rats, and short bouts of social contact increase both of these responses (Brown, 1985a). The effect of social isolation on odor preferences and urine marking by female rats has not been studied nor has the effect of rearing conditions on the development of these behaviors. The purpose of the present experiments is to study these effects.

\section{EXPERIMENT 1}

Previous experiments have shown that gender, gonadal hormone level, and the odor stimuli presented during the test influence the responses of rats to the odors of conspecifics. Male rats spend more time investigating conspecific odors and urine mark more over these odors than do females. Gonadectomy reduces the time spent investigating odors by male and female rats and virtually eliminates their urine-marking behavior. Hormone replacement reinstates both odor investigation and urinemarking responses (Birke, 1978; Brown, 1977, 1978; Price, 1975).

The stimulus odors used to elicit investigation and urinemarking responses have been varied along three dimensions: sex (same vs. opposite sex), familiarity (familiar vs. unfamiliar), and gonadal hormone level (intact vs. gonadectomized). The odor investigation and urinemarking preferences of rats for these odors can be arranged into "affective scales" to compare the responses of different groups of subjects with the same set of odor stimuli (Brown, 1977, 1986).

Both male and female rats spend more time investigating the odors from opposite-sex conspecifics than they spend investigating the odors from same-sex conspecifics, but only males show increased urine marking over these odors (Brown, 1977). Female rats investigate odors from intact males more than they investigate odors from castrated males, and females investigate all male odors more than they investigate female odors. In fact, females investigate female odors only slightly more than they investigate a no-odor stimulus. Females show no preference for urine marking over male odors more than over female odors or nonodorized stimuli (Brown, 1977).

Since total physical isolation from weaning to adulthood disrupts the sexual behavior of adult male rats while social contact with nonreceptive females, other males, or juveniles is sufficient for the normal development of sexual behavior (Hole et al., 1986; Thor \& Flannelly, 1977b), the rats in this study were reared in either social isolation or same-sex social groups. Single-sex rearing does not influence odor investigation or urine-marking responses to conspecific odors (Brown, 1977). Rats' odor investigation and urine-marking responses to a set of five conspecific urine odors and a nonodorized stimulus were examined in a series of 15 pairwise preference tests.

\section{Method}

Subjects

Eighteen male and 18 female Long-Evans hooded rats from nine litters born at Dalhousie University to parents purchased from Charles River Canada (St. Constant, Quebec) were reared with their dams in heterosexual litters of 8 to 12 pups, until they were weaned at 22 days of age. Using a split-litter design, 2 males and 2 females from each litter were placed into each of four groups: individually reared males, individually reared females. group-reared males, and group-reared females ( $n=9$ per group). The individually reared rats were housed in $18 \times 24 \times 18 \mathrm{~cm}$ hanging stainless steel cages with solid sides and wire mesh floors and fronts, so they could not see the rats in adjacent cages, but could hear and smell them. The group-reared rats were housed with two unrelated same-sex rats in $41.5 \times 24 \times 18 \mathrm{~cm}$ cages of the same design. Both groups of male rats were housed in the same room; the two groups of females were housed in a separate room. Each housing room was on a reversed 12:12 light:dark cycle, with lights off at 10:00 a.m. Purina Lab Chow and water were provided ad lib throughout the experiment. None of the rats had heterosexual experience.

Tests began when the rats were 165 days of age (after 143 days of differential housing). During this housing period, the rats were handled and weighed once each week. At the start of the odor preference tests, the group-reared males weighed slightly more than the isolated males (472.2 vs, $451.8 \mathrm{~g}$ ), but this difference was not significant $[t(16)=0.86]$. Likewise, group-reared females were heavier than isolated females $(274.2$ vs. $267.8 \mathrm{~g})$, but this difference was nonsignificant $[t(16)=0.47]$

\section{Urine Donors}

Urine was collected from the individually housed male $(M)$ and female (F) subjects in the experiment. In addition, urine was collected from 6 ovariectomized females (Fo) and 6 castrated males (Mc) who were the same age as the test subjects and had been gonadectomized at 60 days of age.

Urine was collected by attaching a custom-made stainless steel funnel beneath the animal's home cage so that urine could be collected without disturbing the donor. The funnels had two layers of wire mesh ( 0.5 and $0.2 \mathrm{~cm}^{2}$ ) and the top of the urine collection bottle was covered in gauze bandage to prevent feces and other debris from landing in the urine (Brown, 1988). The group-housed animals were placed temporarily in individual cages for urine collection for 2-3 h between 9:00 a.m. and 12:00 noon on days when their urine was required as a stimulus odor.

\section{Test Procedure}

Odor investigation and urine-marking tests were conducted in clear plastic arenas $(23 \times 43 \times 16 \mathrm{~cm})$ placed on a Lucite tabletop covered with unprinted newsprint. Odors were presented by placing $.05 \mathrm{ml}$ urine from a syringe onto a $10 \times 5 \times 2.5 \mathrm{~cm}$ wire mesh block covered with a $20 \times 20 \mathrm{~cm}$ piece of paper towel that was held in place with masking tape. Two of these blocks were used in each test, one at each end of the test arena. Test arenas and wire blocks were used only once per day and then washed with warm soapy water, rinsed, and let dry overnight. The newsprint was changed and the tabletop washed with warm water following each test

Each rat was tested with all pairs of six different odors, resulting in $155-\mathrm{min}$ preference tests. The odors used included the nonodorized, or neutral, odor $(N)$ and urine from intact males $(M)$, castrated males $(\mathbf{M c})$, intact females $(F)$, ovariectomized females (Fo), and the animal's own odor $(O)$. For the group-reared subjects, own odor $(O)$ consisted of urine pooled from at least 2 of the 3 rats in their rearing group. 


\section{Data Recording}

Investigation time. For each of the 15 pairwise odor tests, the time spent sniffing or manipulating each odorized block was recorded on a running time meter using a set of pushbuttons.

Urine marking. After the completion of each 5-min odor preference test, the paper towel covering each block was removed and the areas covered by urine marks were outlined in pencil. A graduated plastic cover plate was then used to calculate the area marked over each block in centimeters squared $\left(\mathrm{cm}^{2}\right)$. The transformation $X=\log _{10}(X+1) \mathrm{cm}^{2}$ was then used to establish homogeneity of variance within groups.

\section{Data Analysis}

Investigation time. Two aspects of the data are of interest: the absolute time spent investigating each of the six odors and the preference for each odor relative to the other five. To compare the absolute odor investigation scores, the mean time spent investigating each odor was averaged over the five tests in which that odor was paired with all other odors. Split-plot ANOVAs were then used to compare the investigation time by isolated versus socially reared males and females $(2 \times 2 \times 6)$ and by isolated versus group-reared rats of each sex $(2 \times 6)$. While these analyses allow for a comparison of the absolute responsiveness of the subjects in each group to the stimulus odors, they do not make use of the information from the difference scores in the 15 pairwise tests. This information is necessary to determine odor preference scales, which are used to explain the interactions between sex, rearing condition, and odor stimuli.

To calculate the relative odor preferences, as defined by Irwin (1958), within each group of rats and to compare preferences across groups, affective scales were calculated for each group using the scaling procedure described by Brown (1977; see also Brown \& Willner, 1983). This procedure arranges the mean difference scores for each of the 15 tests in the upper triangle of a $6 \times 6$ odor matrix, with the negative values in the lower left triangle and the main diagonal left empty. The cell means are the mean difference scores in this matrix, and the scale means are calculated by dividing the column sums by the number of odors (six in this experiment). The scale means can then be used to predict the 15 observed cell means and a residual, calculated by subtracting the predicted cell mean from that actually calculated from the sample data. The better the scale means account for the observed data, the smaller this residual will be. Analysis of variance is then used to partition the between cells sum of squares into that accounted for by the scale means and that left as a residual. For the groups with significant
$F$ values for the scale means, post hoc tests are conducted using the method of Rodger $(1974,1975)$ to determine which scale means differ from each other. These decisions are then represented by a set of implied population scale means. By using the error variance pooled over all four groups of rats in the ANOVAs and setting the implied mean for the neutral odor $(\mathrm{N})$ at zero, the resulting interval scales for odor preferences can be used to interpret group $\times$ odor interactions.

Urine marking. As with investigation scores, both absolute values and difference scores for urine marking were analyzed. To compare absolute levels of urine marking, the areas urine marked over each odor were averaged over the five tests in which that odor was paired with all other odors and split-plot ANOVAs were conducted as described for investigation time. To calculate whether the subjects in each group showed preferences for urine marking over particular conspecific odors, the scaling procedure described above was conducted on the urine-marking difference scores.

\section{Results}

\section{Investigation Scores}

Absolute scores. Table 1 shows the mean time spent investigating each odor (averaged over the five tests with that odor) by the subjects in each of the four groups. The males spent more time investigating odors than did the females $[F(1,32)=53.03, p<.001]$, and although there was no main effect of rearing on investigation time $[F(1,32)<1.0]$, there was a significant interaction between sex and rearing $[F(1,32)=5.51, p<.05]$. The grouped and the isolated males did not differ with respect to time spent investigating odors $[F(1,16)=1.66]$, but the isolated females investigated odors more than did the grouped females $[F(1,16)=5.76, p<.05]$. There was a significant effect of odor stimuli $[F(5,160)=11.78$, $p<.001]$; there were significant interactions between sex and odor $[F(5,160)=2.63, p<.05]$ and between rearing and odor $[F(5,160)=3.16, p<.01]$.

Preference scales. The isolated males, group-reared males, and group-reared females had significant preference scales, which accounted for between $66 \%$ and $75 \%$ of the variability among cell means. The isolated females did not show significant odor preference scales (Table 2).

Table 1

Mean Times ( \pm SEM) Spent Investigating Each Stimulus Odor Averaged Over All Five Tests in which that Odor Was Used and Mean Log Areas ( \pm SEM) Urine Marked Over Each Odor in Experiment 1

\begin{tabular}{|c|c|c|c|c|c|c|c|c|c|c|c|c|}
\hline \multirow[b]{3}{*}{ Subjects } & \multicolumn{12}{|c|}{ Stimulus Odor } \\
\hline & \multicolumn{2}{|c|}{ Neutral } & \multicolumn{2}{|c|}{ Own } & \multicolumn{2}{|c|}{$\begin{array}{l}\text { Intact } \\
\text { Male }\end{array}$} & \multicolumn{2}{|c|}{$\begin{array}{l}\text { Castrated } \\
\text { Male }\end{array}$} & \multicolumn{2}{|c|}{$\begin{array}{l}\text { Ovariectomized } \\
\text { Female }\end{array}$} & \multicolumn{2}{|c|}{$\begin{array}{c}\text { Intact } \\
\text { Female }\end{array}$} \\
\hline & $M$ & $S E M$ & $M$ & $S E M$ & $M$ & $S E M$ & $M$ & $S E M$ & $M$ & $S E M$ & $M$ & $S E M$ \\
\hline \multicolumn{13}{|c|}{ Investigation Time (sec) } \\
\hline Isolated Males & 20.1 & 2.3 & 23.1 & 1.4 & 22.6 & 2.2 & 27.4 & 2.1 & 23.5 & 2.4 & 30.3 & 1.8 \\
\hline Grouped Males & 19.8 & 1.6 & 25.7 & 2.0 & 31.1 & 1.7 & 29.4 & 1.1 & 28.8 & 2.4 & 26.5 & 1.8 \\
\hline Isolated Females & 17.1 & 1.1 & 17.4 & 1.3 & 20.8 & 1.6 & 21.6 & 1.3 & 19.1 & 1.3 & 19.1 & 1.0 \\
\hline Grouped Females & 14.2 & 1.4 & 15.3 & 0.9 & 19.8 & 0.8 & 17.3 & 1.7 & 15.8 & 1.6 & 16.3 & 1.5 \\
\hline \multicolumn{13}{|c|}{ Urine Marking $\left[\log _{10}(X+1) \mathrm{cm}^{2}\right]$} \\
\hline Isolated Males & 0.46 & 0.10 & 0.58 & 0.07 & 0.39 & 0.08 & 0.39 & 0.09 & 0.41 & 0.08 & 0.33 & 0.08 \\
\hline Grouped Males & 0.69 & 0.09 & 0.68 & 0.11 & 0.72 & 0.06 & 0.62 & 0.12 & 0.57 & 0.07 & 0.68 & 0.11 \\
\hline Isolated Females & 0.21 & 0.05 & 0.22 & 0.06 & 0.27 & 0.03 & 0.33 & 0.07 & 0.23 & 0.06 & 0.21 & 0.05 \\
\hline Grouped Females & 0.50 & 0.06 & 0.49 & 0.07 & 0.37 & 0.06 & 0.63 & 0.06 & 0.46 & 0.06 & 0.54 & 0.09 \\
\hline
\end{tabular}


Table 2

Summary of Analyses of Variance for Investigation Time and Urine-Marking Preference Scales in Experiment 1

\begin{tabular}{|c|c|c|c|c|}
\hline Subjects & $\begin{array}{c}\text { Scale } \\
\text { Means } \\
F \\
\end{array}$ & $\begin{array}{c}\text { Residual } \\
F \\
\end{array}$ & $\begin{array}{c}\% \text { of Variation } \\
\text { Among Cell } \\
\text { Means Accounted } \\
\text { for by } \\
\text { Scale Means }\end{array}$ & $\begin{array}{c}\text { Correlation } \\
\text { Between } \\
\text { Implied Means } \\
\text { and Scale } \\
\text { Means } \\
\end{array}$ \\
\hline \multicolumn{5}{|c|}{ Investigation Time } \\
\hline $\begin{array}{l}\text { Isolated Males } \\
\text { Grouped Males } \\
\text { Isolated Females } \\
\text { Grouped Females }\end{array}$ & $\begin{array}{l}9.50^{*} \\
4.61^{*} \\
2.12 \\
6.99^{*}\end{array}$ & $\begin{array}{l}1.61 \\
1.14 \\
2.50^{*} \\
1.27\end{array}$ & $\begin{array}{l}74.72 \\
66.83 \\
29.83 \\
73.35\end{array}$ & $\begin{array}{l}.960 \\
.943 \\
.946\end{array}$ \\
\hline \multicolumn{5}{|c|}{ Urine Marking } \\
\hline $\begin{array}{l}\text { Isolated Males } \\
\text { Grouped Males } \\
\text { Isolated Females } \\
\text { Grouped Females }\end{array}$ & $\begin{array}{l}4.67^{*} \\
0.93 \\
0.29 \\
0.81\end{array}$ & $\begin{array}{l}0.80 \\
0.99 \\
0.67 \\
0.87\end{array}$ & $\begin{array}{l}74.60 \\
31.98 \\
17.81 \\
31.59\end{array}$ & .922 \\
\hline
\end{tabular}

Note-For investigation time, the pooled error variance was 0.047 . For urine marking, the pooled error variance was 0.324 . Rodger's $(1975)$ critical $F$ values at the .01 level are $F(5,480)=2.31$ for scale means and $F(10,480)=1.66$ for the residuals. $\quad * p<.01$.

Post hoc analyses of the scale means resulted in the implied population preference scale means shown in Figure 1. These implied means correlate highly with the sample scale means (Table 2), indicating that the decisions based on the post hoc tests are in agreement with the sample data. Since a common variance was used to calculate the implied means for each group, all implied means in Figure 1 can be compared with each other.

The isolated males showed the preference scale $\mathrm{N}<\mathrm{O}=\mathbf{M}=\mathrm{Fo}_{\mathrm{O}}<\mathrm{Mc}<\mathrm{F}$, with implied means of $0.0,0.62,0.62,0.62,0.84$, and $1.50 \sigma$ (standard deviation) units. Since differences of $0.4 \sigma$ units or more are quite large (see Brown, 1977), the isolated males showed substantial preferences for all rat odors over the neutral odor (at least $0.62 \sigma$ units) and a significant preference for odors of intact females over all other conspecific odors (at least .66 $\sigma$ units); however, the preference for odors

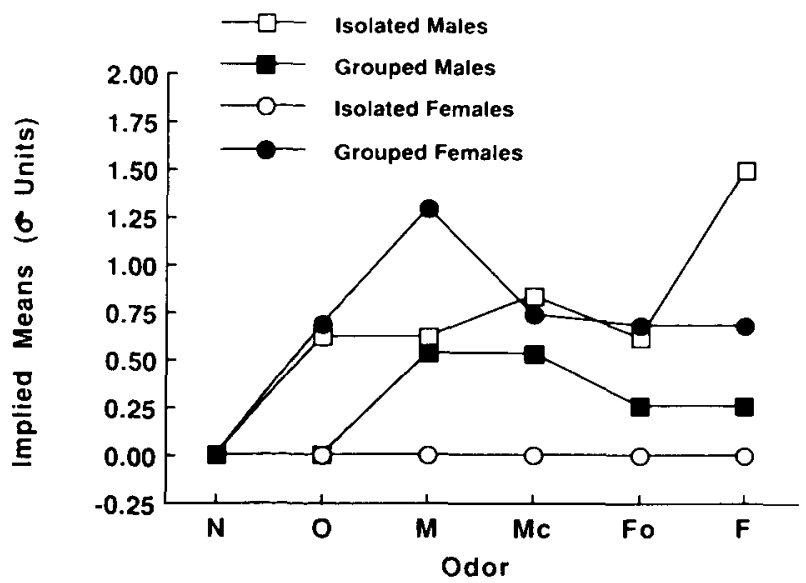

Figure 1. Implied population scale means for odor preference scales of isolated and group-reared males and females in Experiment 1. Implied means for the neutral odor $(N)$ have been set to zero. Abbreviations for the other odors are $O=$ own, $M=$ intact male, Mc $=$ castrated male, Fo $=$ ovariectomized female, and $F=$ intact female. of the castrated males over those of own odor, intact males, and ovariectomized females was much smaller $(0.22 \sigma$ units) and thus not as reliable.

The group-reared males had the preference scale $\mathrm{N}=\mathrm{O}<\mathrm{Fo}=\mathrm{F}<\mathrm{M}=\mathrm{Mc}$, with implied means of $0.0,0.0,0.26,0.26,0.53$, and $0.53 \sigma$ units. The differences $\mathbf{M}>\mathrm{N}$ and $\mathrm{Mc}>\mathrm{N}$ were quite substantial ( $0.53 \sigma$ units), whereas the preferences for female odors over the neutral odor ( $0.26 \sigma$ units) and the preferences for male odors over those of females $(0.27 \sigma$ units) were much smaller and of less significance.

The group-reared females showed the preference scale $\mathbf{N}<\mathbf{O}=\mathrm{Fo}_{\mathrm{O}}=\mathrm{F}<\mathrm{Mc}<\mathrm{M}$, with implied means of $0.0,0.68,0.68,0.68,0.74$, and $1.29 \sigma$ units. The preferences for conspecific odors over the neutral odor were all quite substantial (at least $0.68 \sigma$ units), as was the preference for odor of intact males over those of other rats (at least $0.55 \sigma$ units), but the preference for odors of castrated males over own odors and those of other females ( $0.06 \sigma$ units) was negligible. Since the isolated females did not have a significant preference scale, all odors have the same implied population scale value as the neutral odor $(\mathrm{N}=0.0)$.

\section{Urine Marking}

Absolute scores. The mean areas urine marked over each stimulus odor (averaged over the five tests with that odor) by the subjects in each of the four groups are also shown in Table 1 . The males urine marked more than did the females $[F(1,32)=9.86, p<.01]$, and the groupreared rats urine marked more than did those reared in isolation $[F(1,32)=19.98, p<.001]$, with no rearing $x$ sex interaction $(F<1.0)$. The group-reared males urine marked more than did the isolates $[F(1,16)=6.47$, $p<.05]$, as did the group-reared females $[F(1,16)$ $=19.14, p<.01]$. There was a significant interaction between the sex of the subjects and the stimulus odor $[F(5,160)=2.27, p<.05]$, but no other interactions were significant. 


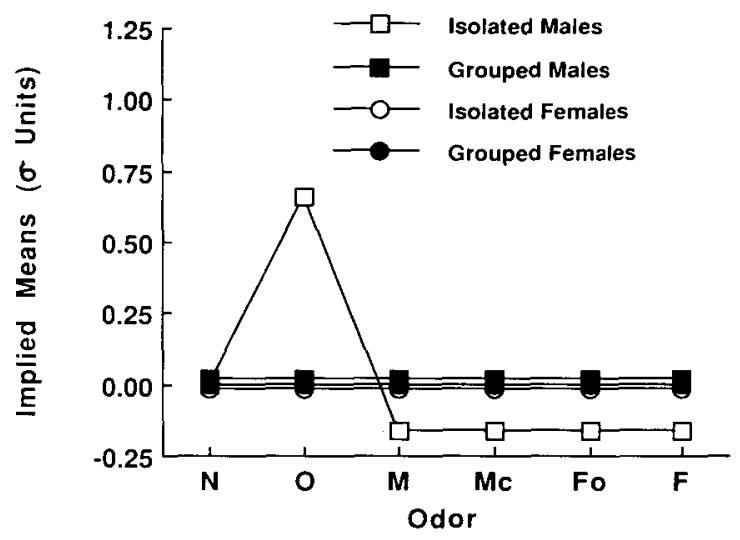

Figure 2. Implied population scale means for urine-marking preference scales of isolated and group-reared males and females in Experiment 1. $N=$ neutral odor, $O=$ own odor, $M=$ intact male odor, $\mathrm{Mc}=$ castrated male odor, Fo $=$ ovariectomized female odor, and $F=$ intact female odor.

Preference scales. Only the isolated males showed a significant marking preference scale (Table 2). The isolated males showed the preference scale $\mathbf{M}=\mathbf{M c}=$ Fo $=F<N<O$, with implied means of -0.16 , $-0.16,-0.16,-0.16,0.0$, and $0.66 \sigma$ units (Figure 2). There was a preference for marking over their own odors (0.66 $\sigma$ units) and a slight aversion to marking over the odors of other rats. Because these negative scale means are only slightly less than zero ( $-0.16 \sigma$ units), one cannot be too confident about the differences.

The group-reared males marked most over the odors of the intact males; the isolated and group-reared females marked most over the odors of castrated males (Table 1). However, these groups did not have significant $F$ values for scale means (Table 2), so the implied means are all equal to that for the neutral odor $(\mathrm{N}=0.0)$.

\section{Discussión}

The results of Experiment 1 indicate that rearing condition influenced the absolute time spent investigating odors by males, but not by females, and influenced the absolute levels of urine marking by both males and females (Table 1). Gender also influenced odor investigation and urine-marking scores, with the males spending more time investigating odors and urine marking more over these odors than did the females. Rearing condition influenced the odor investigation preference scales for both the males and the females and the urine-marking preference scales of the males, but not the females.

The group-reared females in Experiment 1 showed almost exactly the same pattern of odor preferences as did the intact females in a previous experiment (Brown, 1977); social isolation, like ovariectomy, eliminated these preferences. Neither the group-reared nor the individually reared females showed any preferences for urine marking over odors, nor did the group-reared males; however, the isolated males showed a strong preference for marking over their own odor. Female rats had not previously shown preferences for selectively urine marking conspecific odors (Brown, 1977), so, although individual rearing reduced the absolute amount of urine-marking by females in this experiment, the pattern of marking was not affected.

It is difficult to assess the effects of social isolation on the odor investigation and urine-marking responses of males in Experiment 1 because the group-reared males did not show the investigation and urine-marking preferences for female odors, which was expected from previous results (Brown, 1977, 1985a, 1986). The group-reared males showed the highest preferences for investigating odors of other males (Figure 1) and had a tendency (although not significant) to urine mark more over the odors of other males (Table 1). These results suggest that the group-reared males developed a male odor preference rather than a female odor preference.

Males are attracted to the odors of other males, but generally prefer the odors of females (Brown, 1977, 1986). Sexually naive adult males housed in individual cages for 60 days show slightly higher investigation and urine marking of male odors than female odors (Brown, 1985b), suggesting that familiarity only with male odors may increase responses to these odors.

The individually housed males showed the highest preference for female odors, but urine marked most over their own odor. Male rats generally mark over their own odors at about the same amount as over a nonodorized object (Brown, 1975, 1977, 1985a). The isolated rats may have urine marked over their own odor more than the others because this was the only odor that was familiar to them.

Taken in combination with the results of previous experiments, the present results allow us to conclude that isolation rearing disrupts the odor preferences and reduces the total amount of urine marking by female rats. We can also conclude that isolation rearing reduces urine marking by male rats, but the effects of isolation rearing on the odor preference and urine-marking scales of male rats cannot be determined because of the unexpected results of the group-housed males. For this reason, a second experiment on the effects of isolation rearing on odor preferences and urine marking in male rats was conducted.

\section{EXPERIMENT 2}

Because the results of the group-reared males in Experiment 1 were not those expected from previous studies, Experiment 2 examined more closely the effects of rearing experience on odor investigation and urine marking in male rats. One variable that was not examined in Experiment 1 is the role of sexual experience in adulthood on odor preferences. Sexual experience increases the preferences of male rats for investigating female odors (Brown, 1977) and produces a preference for the odors of estrous females over those of diestrous females (Carr, Loeb, \& Dissinger, 1965; Lydell \& Doty, 1972), but does not increase urine marking over female odors. Sexual ex- 
perience has no influence on the investigation preferences or urine-marking behavior of female rats (Brown, 1977).

Male rats that have been sexually aroused by interacting with females immediately before odor preference tests show no increased investigation of female odors, but they do show an increase in urine marking over both male and female odors (Brown, 1986). Sexual experience was given at least one week prior to the odor preference tests so that the subjects were sexually experienced, but not sexually aroused during the odor preference tests.

The set of stimulus odors used in Experiment 2 was modified slightly from that used in Experiment 1 . Because only male subjects were tested, odors from castrated males were not used; because sexual experience has been shown to increase the preferences for odors of estrous females, these odors were used in Experiment 2.

\section{Method}

\section{Subjects}

Forty male Long-Evans hooded rats from 10 litters born at Dalhousie University to parents purchased from Charles River Canada served as subjects. Upon weaning from their littermates at 22 days of age, a split-litter design was used to place 4 males from each litter into the two rearing groups: 2 males were housed singly in $18 \times 24 \times 18 \mathrm{~cm}$ stainless steel cages (isolates) and 2 males were housed in pairs with unrelated males in $41.5 \times 24 \times 18 \mathrm{~cm}$ cages (group-reared). All rats were housed in the same room, which was on a 12:12 reversed light:dark cycle with lights off at 10:00 a.m. Purina Lab Chow and water were freely available. The subjects were maintained in differential housing conditions until they were 120 days of age ( 98 days of differential housing), then all males were housed individually in the smaller metal cages.

All rats were weighed before the odor preference tests were conducted. Although the sexually experienced $(\bar{x}=457.2 \mathrm{~g})$ and the naive $(\bar{x}=447.2 \mathrm{~g})$ group-reared rats weighed more than did the sexually experienced $(\vec{x}=437.2 \mathrm{~g})$ and the naive $(\bar{x}=406.7 \mathrm{~g})$ isolates, neither rearing condition $[F(1,35)=3.29, p=.074]$ nor sexual experience $[F(1,35)=1.48]$ significantly affected body weight.

\section{Sexual Experience}

At about 130 days of age, half of the individually reared and group-reared males were given sexual experience. Each of these males was paired with an hormonally primed ovariectomized fe- male in a $62 \times 32 \times 31 \mathrm{~cm}$ glass arena and observed for $20 \mathrm{~min}$. Estrus was induced by a $50-\mu \mathrm{g}$ injection of estradiol benzoate (Sigma) $48 \mathrm{~h}$ before testing and $0.5-\mathrm{mg}$ injection of progesterone (Sigma) 4 to $6 \mathrm{~h}$ before testing. If the male achieved intromissions during this period of observation, it was placed with the female in its home cage (a $23 \times 43 \times 16 \mathrm{~cm}$ plastic cage with wood shavings for bedding) for 18 to $20 \mathrm{~h}$. The males that did not intromit during the 20-min observation period were paired with different females every 2 to 3 days until they began to copulate. Each male was given two such sexual experience periods and up to five trials were given in order to obtain two successful sexual experiences. The isolated and group-reared males did not differ in the time to achieve two successful matings, both groups having a mean of 3.1 trials. To control for handling and exposure to a novel environment, the two groups of sexually naive males, on two separate occasions, were placed alone in the clean glass arena for $20 \mathrm{~min}$ and then placed for 18 to $20 \mathrm{~h}$ in a plastic cage with clean wood shavings for bedding.

\section{Urine Donors}

The subjects served as urine donors for own $(\mathrm{O})$ and male $(\mathrm{M})$ odors. In addition, urine was collected from three ovariectomized females (Fo) and three ovariectomized females that had been brought into estrus ( $\mathrm{Fe}$ ) with estrogen and progesterone injections as described above. Urine was collected by placing funnels under the donor's home cage as described in Experiment 1.

\section{Odor Preference Tests}

About a week after the sexual experience phase, each male received 10 odor preference tests, one with each of the possible pairs of five odors: water (a neutral odor, $N$ ), the male's own urine $(\mathrm{O})$, urine from unfamiliar intact males $(\mathrm{M})$, ovariectomized females (Fo), and estrus-induced females ( $\mathrm{Fe}$ ). One isolation-reared, sexually naive male died before the odor preference tests began, leaving 9 males in this group and 10 in each of the other three groups.

\section{Test Procedure, Data Collection, and Analysis}

Urine was dropped on the paper-towel-covered stimulus blocks using a syringe. The investigation times and areas urine marked were recorded and analyzed as described in Experiment 1

\section{Results}

\section{Investigation Times}

Absolute scores. The mean time spent investigating each odor (averaged over the four tests with that odor) by the subjects in each group is shown in Table 3 . The

Table 3

Mean Times ( \pm SEM) Spent Investigating Each Odor and Mean Log Urine-Marking Scores Averaged Over All Four Tests in which that Odor was Presented in Experiment 2

\begin{tabular}{|c|c|c|c|c|c|c|c|c|c|c|}
\hline \multirow[b]{3}{*}{ Subjects } & \multicolumn{10}{|c|}{ Stimulus Odor } \\
\hline & \multicolumn{2}{|c|}{ Neutral } & \multicolumn{2}{|c|}{ Own } & \multicolumn{2}{|c|}{$\begin{array}{l}\text { Intact } \\
\text { Male }\end{array}$} & \multicolumn{2}{|c|}{$\begin{array}{l}\text { Ovariectomized } \\
\text { Female }\end{array}$} & \multicolumn{2}{|c|}{$\begin{array}{l}\text { Estrous } \\
\text { Female }\end{array}$} \\
\hline & $M$ & SEM & $M$ & SEM & $M$ & SEM & $M$ & SEM & $M$ & $S E M$ \\
\hline \multicolumn{11}{|c|}{ Investigation Time (sec) } \\
\hline Isolated Sex & 44.6 & 5.4 & 45.7 & 6.8 & 46.9 & 5.4 & 61.2 & 7.1 & 57.9 & 5.8 \\
\hline Isolated No Sex & 44.7 & 6.6 & 46.0 & 6.7 & 40.8 & 5.4 & 42.0 & 8.6 & 43.8 & 7.3 \\
\hline Grouped Sex & 30.3 & 3.7 & 31.7 & 3.8 & 28.4 & 3.5 & 50.0 & 5.8 & 49.0 & 4.9 \\
\hline Grouped No Sex & 26.2 & 2.5 & 27.6 & 3.6 & 31.8 & 3.1 & 37.9 & 5.1 & 40.8 & 3.7 \\
\hline \multicolumn{11}{|c|}{ Urine Marking $\left[\log _{10}(X+1) \mathrm{cm}^{2}\right]$} \\
\hline Isolated Sex & 0.53 & 0.15 & 0.31 & 0.10 & 0.49 & 0.15 & 0.52 & 0.16 & 0.47 & 0.15 \\
\hline Isolated No Sex & 0.10 & 0.05 & 0.17 & 0.08 & 0.20 & 0.12 & 0.12 & 0.07 & 0.11 & 0.08 \\
\hline Grouped Sex & 0.47 & 0.12 & 0.25 & 0.09 & 0.41 & 0.13 & 0.81 & 0.16 & 0.76 & 0.13 \\
\hline Grouped No Sex & 0.50 & 0.40 & 0.09 & 0.04 & 0.24 & 0.11 & 0.17 & 0.09 & 0.29 & 0.13 \\
\hline
\end{tabular}




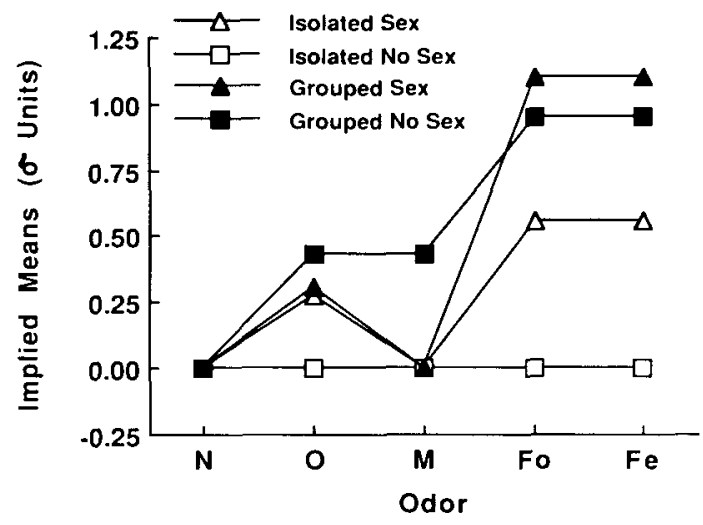

Figure 3. Implied population scale means for odor preference scales of sexually experienced and naive isolated and group-reared males in Experiment 2. $\mathbf{N}=$ neutral odor, $O=$ own odor, $M=$ intact male odor, $\mathrm{Fo}_{\mathrm{O}}=$ ovariectomized female odor, and $\mathrm{Fe}=$ estrous female odor.

isolated males spent more time investigating odors than did the group-reared males $[F(1,35)=7.49, p<.01]$, but sexual experience did not affect the time investigating odors $[F(1,35)=2.12]$. There was not a significant interaction between rearing condition and sexual experience $[F(1,35)<1.0]$. There was a significant effect of stimulus odors on investigation time $[F(4,140)=11.31$, $p<.001]$ and significant interaction between sexual experience and odor $[F(4,140)=3.36, p<.01]$, but no significant rearing $\times$ odor interaction $[F(4,140)=2.01]$.

Preference scales. The sexually experienced isolated males, the sexually naive group-reared males, and the sexually experienced group-reared males had significant scale means (Table 3). These scale means accounted for between $58 \%$ and $91 \%$ of the variability between cell means. Only the sexually naive isolated males failed to show a significant odor preference scale. The implied population scale means for odor investigation preference scales based on the decisions from post hoc tests are shown in Figure 3 . These implied means correlate highly with the sample scale means (Table 4), and, therefore, the decisions accurately reflect the data.

The sexually experienced isolated males showed the odor preference scale $\mathbf{N}=\mathbf{M}<\mathrm{O}<\mathrm{Fo}=\mathrm{Fe}$, with scale means of $0.0,0.0,0.28,0.56$, and $0.56 \sigma$ units. While the preferences for female odors over the neutral and male odors were quite substantial (0.56 $\sigma$ units), the preferences for female odors over own odor and for own odor over the neutral odor ( $0.28 \sigma$ units) were much smaller. Since the sexually naive isolated males did not show a significant preference scale, the implied means were all equal to that of the neutral odor $(\mathrm{N}=0.0)$.

The sexually experienced group-reared males had the preference scale $\mathbf{N}=\mathbf{M}<\mathrm{O}<\mathrm{Fo}=\mathrm{Fe}$, with implied means of $0.0,0.0,0.31,1.10$, and $1.10 \sigma$ units, respectively. The preference for female odors over the other odors was quite substantial (at least $0.79 \sigma$ units), whereas the preference for own odors over those of other males was much less pronounced ( $0.31 \sigma$ units). The sexually naive group-reared males showed the odor preference scale $\mathrm{N}<\mathrm{O}=\mathrm{M}<\mathrm{Fo}=\mathrm{Fe}$, with implied means of $0.0,0.43,0.95$, and $0.95 \sigma$ units. All of these differences were quite substantial (at least $0.43 \sigma$ units), thus the preferences for female odors over own and male odors and the preferences for all odors over the neutral odor should be very reliable.

\section{Urine Marking}

Absolute scores. The mean log areas urine marked over each odor (averaged over the four tests with that odor) by the subjects in each group are shown in Table 3 . There was a significant effect of sexual experience on the amount of urine marking $[F(1,35)=12.80, p<.001]$ but no ef-

Table 4

Summary of Analyses of Variance for Investigation Time and Urine-Marking Preference Scales in Experiment 2

\begin{tabular}{|c|c|c|c|c|}
\hline Subjects & $\begin{array}{c}\text { Scale } \\
\text { Means } \\
F \\
\end{array}$ & $\begin{array}{c}\text { Residual } \\
F \\
\end{array}$ & $\begin{array}{c}\text { \% of Variation } \\
\text { Among Cell } \\
\text { Means Accounted } \\
\text { for by } \\
\text { Scale Means } \\
\end{array}$ & $\begin{array}{c}\text { Correlation } \\
\text { Between } \\
\text { Implied Means } \\
\text { and Scale } \\
\text { Means } \\
\end{array}$ \\
\hline \multicolumn{5}{|c|}{ Investigation Time } \\
\hline Isolated Sex & $3.61^{*}$ & 1.70 & 58.54 & .957 \\
\hline Isolated No Sex & 2.29 & 1.95 & 43.92 & \\
\hline Grouped Sex & $10.58 *$ & 0.68 & 91.23 & .999 \\
\hline Grouped No Sex & $7.48 *$ & 0.84 & 85.65 & .981 \\
\hline \multicolumn{5}{|c|}{ Urine Marking } \\
\hline Isolated Sex & $3.11^{*}$ & 0.21 & 83.24 & .975 \\
\hline Isolated No Sex & 0.68 & 0.33 & 57.99 & \\
\hline Grouped Sex & $2.67 *$ & 1.79 & 49.79 & .981 \\
\hline Grouped No Sex & 1.00 & 1.02 & 39.50 & \\
\hline
\end{tabular}

Note-For investigation time, the pooled error variance was 0.108 . For urine marking, the pooled error variance was 0.287 . Rodger's (1975) critical $F$ values at the .01 level are $F(4,370)=2.64$ for scale means and $F(6,370)=2.12$ for the residuals. $\quad{ }^{*} p<.01$. 


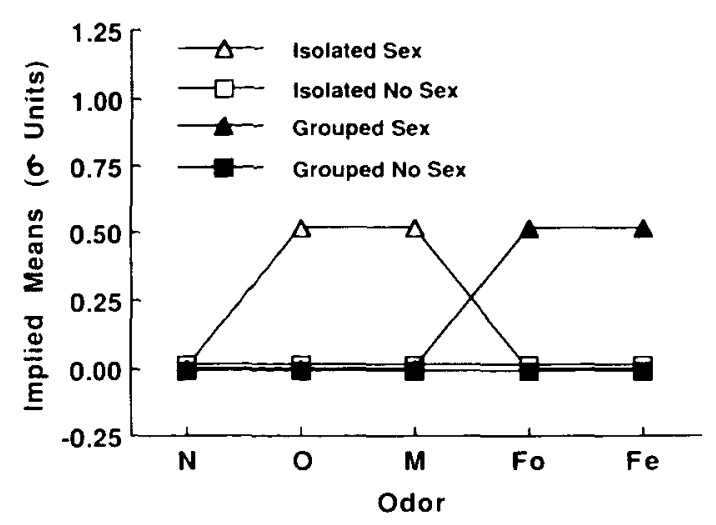

Figure 4. Implied population scale means for urine-marking preference scales of sexually experienced and naive isolated and group-reared males in Experiment 2. $N=$ neutral odor, $O=$ own odor, $\mathbf{M}=$ intact male odor, Fo = ovariectomized female odor, and $\mathrm{Fe}=$ estrous female odor.

fect of rearing $[F(1,35)<1.0]$ and no interaction between rearing and sexual experience $[F(1,35)<1.0]$. Sexual experience increased the amount of urine marking by both the isolated males $[F(1,16)=12.91$, $p<.01]$ and the group-reared males $[F(1,16)=6.79$, $p<.05]$. There was a significant interaction between rearing condition and odor $[F(4,140)=2.44, p<.05]$, but no other interactions were significant.

Preference scales. The sexually experienced isolated and group-reared males showed significant marking scale means, which accounted for $83 \%$ and $49 \%$ of the variability among the 10 cell means, respectively (Table 4). Neither the sexually naive isolated males nor the sexually naive group-reared males had significant scale means (Table 4).

The implied means calculated from the decisions of the post hoc tests are shown in Figure 4. The sexually experienced isolated males showed the preference scale $\mathbf{N}=\mathbf{F o}=\mathrm{Fe}<\mathrm{O}=\mathrm{M}$, with implied means of 0.0 , $0.0,0.0,0.52$, and $0.52 \sigma$ units, respectively. The preferences for own odors and the odors of other males were large enough to be reliable ( $0.52 \sigma$ units). The sexually experienced group-reared males showed the preference scale $\mathbf{N}=\mathbf{O}=\mathbf{M}<\mathrm{Fo}=\mathrm{Fe}$, with implied means of $0.0,0.0,0.0,0.52$, and $0.52 \sigma$ units, respectively. The preferences for female odors over the other odors were quite substantial ( $0.52 \sigma$ units). The two groups of sexually naive males had implied means for all odors equal to those for the neutral odor $(\mathrm{N}=0.0)$.

\section{Discussion}

The results of Experiment 2 indicate that both rearing condition and sexual experience influenced odor investigation and urine marking by male rats. Isolation rearing increased the time investigating conspecific odors, but had no effect on the amount of urine marking over these odors. Sexual experience had no effect on the time spent inves- tigating odors but increased the amount of urine marking over these odors (Table 3 ).

Rearing condition and sexual experience interacted to influence the odor investigation and marking preferences of the male rats. The group-reared males showed a greater preference for investigating conspecific odors than did the individually reared males; the preferences for female odors were enhanced by sexual experience in both rearing groups. The group-reared males also showed a greater preference for male odors than did the individually reared males (Figure 3).

The odor investigation and urine-marking preferences of the sexually experienced group-reared males in Experiment 2 were similar to those of sexually experienced males in previous studies (Brown, 1977, 1986), as were the odor investigation preferences of the sexually naive group-reared males. As in Experiment 1, the sexually naive group-reared males showed no preference for urine marking over any conspecific odors.

The interaction between sexual experience and rearing condition found in Experiment 2 indicates that sexual experience in adulthood is sufficient to reinstate normal responses to social odors in isolation-reared males. The results of Experiment 2 suggest that the male rats in Birke and Sadler's (1984) experiment investigated and marked the odors of other males more than those of females because they were reared in small all-male groups and were sexually naive. The sexually naive group-reared males in Experiment 2 showed the results found by Birke and Sadler (1984), while the sexually experienced group-reared rats replicated the results of Brown (1977).

\section{GENERAL DISCUSSION}

The two experiments reported here show that isolation rearing disrupts the development of odor investigation preferences in female and male rats and the urine-marking patterns of male rats. In combination with previous studies, these results provide a framework for understanding the relationship between isolation rearing and olfactory communication in the development of social behavior.

Social odors are important stimuli for eliciting sexual, aggressive, affiliative, and other social behaviors. Rats must be able to associate the odors of conspecifics with appropriate behavioral responses in social situations (Flannelly \& Blanchard, 1982). Although physically isolated rats may have olfactory contact with conspecifics (Brain $\&$ Benton, 1979), they are unable to associate these olfactory signals with behavioral actions (Thor, 1980; Thor \& Flannelly, 1977b). Isolated rats may thus be familiar with the olfactory signals of conspecifics but not with how to react to these signals.

Isolation rearing alters neural dopamine, serotonin, and opiate systems, and changes in the synthesis, storage, or release of these transmitters or in the sensitivity of their receptors will influence social behavior (Brain \& Benton, 1979; Oehler, Jähkel, \& Schmidt, 1987; O’Shea, Saari, 
Pappas, Ings, \& Stange, 1983; Schenk, Britt, Atalay, \& Charleson, 1982; Valzelli, 1973). Likewise, altered neuroendocrine development in isolated animals, particularly in the hypothalamic-pituitary-adrenal and the hypothalamicpituitary-gonadal systems, may also underlie the observed deficiencies in social behavior (Brain \& Benton, 1979; Hatch, Balazs, Wiberg, \& Grice, 1963). Since changes in hormone levels may also alter the urine odors of rats (Brown, 1977, 1979, 1985b), differential housing, through its effects on the neuroendocrine system, may result in changes in urinary odors as well as responses to these odors. Group-housed males, for example, may have different odors related to their dominance status or stress level. It is possible that individual housing may result in altered urine odors of rats, but the effects of housing on urine odor are unclear (see Brown, 1985b, pp. 407-408).

During their initial social interactions, isolated rats often show "competing responses," such as exploration, grooming, and investigation of their social partner $(H$. D. Gerall et al., 1967; Hard \& Larsson, 1968; Sloan \& Latané, 1974). Isolated males spend most of the first $5 \mathrm{~min}$ of an encounter with a strange male in olfactory investigation (Adams, 1976). In a food dominance test, Hoyenga and Lekan $(1970$, p. 56) report that "the isolate-rearing Ss during the early trials tended to smell, push, climb over, and in general thoroughly explore the 'novel' socially reared S rather than eat." These competing responses may be attempts to seek olfactory information about the social partner. Thus, social grooming and investigation during group housing may be the crucial variables for the development of normal social behavior (Gruendel \& Arnold, 1974) because they allow rats to gain olfactory information about conspecifics and associate this information with appropriate behavioral responses.

Animals must have some basis for discriminating between the odors of conspecifics (Brown, 1979) and this basis appears to be their own social experience. As shown by the results of Experiment 2 and those of others (e.g., Fillion \& Blass, 1986; Nyby, Whitney, Schmitz, \& Dizinno, 1978), this experience may occur during development or in adulthood. The fact that short periods of social contact after isolation rearing can reinstate nearly normal social behavior (Brown, 1985a; Gentsch, Lichtsteiner, Frischknecht, Feer, \& Siegfried, 1988; H. D. Gerall et al., 1967) and that anosmia inhibits the development of appropriate behavior following experience in a variety of social situations (Labov \& Wysocki, 1989; Matochik, 1988; Thor \& Flannelly, 1977b, 1978; Wilhelmsson \& Larsson, 1973) further supports the hypothesis that olfactory learning is a major component of social experience. The increased responses to own odor and the odors of other males in males reared in isolation and small all-male groups reflect the odor associations formed under these restricted rearing conditions.

Olfactory associations learned during development result in neural changes that persist to adulthood (Coopersmith \& Leon, 1986; Sullivan, Wilson, \& Leon, 1989); social isolation deprives the rat of the conspecific olfac- tory stimuli that may be necessary to shape its neural development. Social experience after isolation may normalize the neurochemical and neuroendocrine imbalances caused by isolation rearing (Gentsch et al., 1988; Oehler et al., 1987; Pappas et al., 1987). Thus, the development of normal social behavior after isolation rearing may depend on socially induced changes in the neurotransmitters and hormones underlying the learning of conspecific olfactory signals.

Scent marking in rats, as in other mammals, is controlled by the animal's motivational state and by the presence of external stimuli (Brown, 1986; Johnson, 1973). While I have argued that olfactory communication via urine marking in rats serves a sexual advertisement function (Brown, 1977, 1986), other researchers have suggested that urine marking is a response to novelty (Hopp \& Timberlake, 1983), a response to the familiarity of nonsexual social odors (Birke \& Sadler, 1984), or a mechanism for advertising the reproductive state of the individual (Lee, Mitchell, \& Adams, 1984). Socially experienced male rats mark more than do isolates (Experiment 2 of the present study), dominant males mark more than do subordinates (Adams, 1976), sexually aroused males mark more than do nonaroused males (Brown, 1986), and estrous females mark more than do diestrous females (Birke, 1978); these differences may reflect different levels of self advertisement. Male and female rats can be identified by their individual odors (Brown, 1988), and the individuality of the urine mark may be an important component of the social signal.

In summary, the mechanisms through which isolation rearing alters social behavior may be as follows. The socially isolated rat has a number of neurochemical and neuroendocrine abnormalities and lacks the opportunity for olfactory learning. When placed in a social situation, olfactory learning via social investigation and exploratory behavior begin to occur as soon as the social partner is encountered. Because of their neurochemical imbalances, however, isolates learn more slowly and make more errors than do socially reared animals, even in nonsocial learning tasks (Juraska, Henderson, \& Müller, 1984; Pappas et al., 1987), so the abnormal social behavior persists for some time. With prolonged social contact, however, the relationships between conspecific odors and social responses are learned, so normal social behavior gradually develops. Anosmia prevents the complete rehabilitation of social behavior in isolates because the olfactory learning component cannot occur. The predominance of olfactory communication in mammalian social behavior (Brown, 1979, 1985b) and the evidence that effective social behavior requires the learning of conspecific olfactory signals indicate that understanding the mechanism of this olfactory learning is an important area for future research on the development of social behavior.

\section{REFERENCES}

ADAMs, D. B. (1976). The relation of scent-marking, olfactory investigation, and specific postures in the isolation-induced fighting of rats. Behaviour, 56, 286-297. 
Alberts, J. R., GAlef, B. G., JR. (1973). Olfactory cues and movement: Stimuli mediating intraspecific aggression in the wild Norway rat. Journal of Comparative \& Physiological Psychology, 85, 233-242.

BiRKE, L. I. A. (1978). Scent-marking and the oestrous cycle of the female rat. Animal Behaviour, 26, 1165-1166.

BiRKE, L. I. A., \& SADLER, D. (1984). Scent-marking behaviour in response to conspecific odours by the rat, Rattus norvegicus. Animal Behaviour, 32, 493-500.

Brain, P., Benton, D. (1979). The interpretation of physiological correlates of differential housing in laboratory rats. Life Sciences, 24, 99-116.

Brown, R. E. (1975). Object-directed urine-marking by male rats (Rattus norvegicus). Behavioral Biology, 15, 251-254.

Brown, R. E. (1977). Odor preference and urine-marking scales in male and female rats: Effects of gonadectomy and sexual experience on responses to conspecific odors. Joumal of Comparative \& Physiological Psychology, 91, 1190-1206.

Brown, R. E. (1978). Hormonal control of odor preferences and urinemarking in male and female rats. Physiology \& Behavior, 20, 21-24.

Brown, R. E. (1979). Mammalian social odors: A critical review. Advances in the Study of Behavior, 10, 103-162.

Brown, R. E. (1985a). Effects of social isolation in adulthood on odor preferences and urine-marking in male rats. Behavioral \& Neural Biology, 44, 139-143.

Brown, R. E. (1985b). The rodents: II. Suborder Myomorpha. In R. E. Brown \& D. W. Macdonald (Eds.), Social odours in mammals (Vol. 1 , pp. 345-457) Oxford: Clarendon Press.

Brown, R. E. (1986). A motivational analysis of odor investigation and urine-marking in male rats (Rattus norvegicus). Psychological Record, 36, 69-79.

Brown, R. E. (1988). Individual odors of rats are discriminable in dependently of changes in gonadal hormone levels. Physiology \& Behavior, 43, 359-363.

Brown, R. E., Willner, J. A. (1983). Establishing an "affective scale" for odor preferences of infant rats. Behavioral \& Neural Biology, 38, 251-260.

CARr, W. J., Loeb, L. S., \& Dissinger, M. L. (1965). Responses of rats to sex odors. Journal of Comparative \& Physiological Psychology, 59, 370-377.

CoOpersmith, R., \& LEON, M. (1986). Enhanced neural response by adult rats to odors experienced early in life. Brain Research, 371, 400-403.

DalRymple-Alford, J. C., \& BeNTON, D. (1981). Activity differences of individually and group-housed male and female rats. Animal Learning \& Behavior, 9, 50-55.

Day, H. D., Seay, B. M., Hale, P., \& Hendricks, D. (1982). Early social deprivation and the ontogeny of unrestricted social behavior in the laboratory rat. Developmental Psychobiology, 15, 47-59.

DufFy, J. A., Hendricks, S. E. (1973). Influences of social isolation during development on sexual behavior of the rat. Animal Leaming \& Behavior, 1, 223-227.

FILlion, T. J., \& Blass, E. M. (1986). Infantile experience with suckling odors determines adult sexual experience in male rats. Science, 231, 729-731.

Flannelly, K. J., Blanchard, R. J. (1982). Decreased aggressive and social responsiveness of chronically anosmic male rats. Bulletin of the Psychonomic Society, 19, 173-176.

Gentsch, C., Lichtsteiner, M., Frischknecht, H.-R., Feer, H., * Siegrried, B. (1988). Isolation-induced locomotor hyperactivity and hypoalgesia in rats are prevented by handling and reversed by resocialization. Physiology \& Behavior, 43, 13-16.

Gerall, H. D., Ward, I. L., \& Gerall, A. A. (1967). Disruption of the male rat's sexual behaviour induced by social isolation. Animal Behaviour, 15, 54-58.

Gruendel, A. D., \& ARNOLD, W. J. (1974). Influence of preadolescent experiential factors on the development of sexual behavior in albino rats. Journal of Comparative \& Physiological Psychology, 86, 172-178.
HANSEN, S. (1977). Mounting behavior and receptive behavior in developing female rats and the effect of social isolation. Physiology \& Behavior, 19, 749-752.

HARD, E., LARsSon, K. (1968). Dependence of adult mating behavior in male rats on the presence of littermates in infancy. Brain, Behavior \& Evolution, 1, 405-419.

Hatch, A., Balazs, T., Wiberg, G. S., Grice, H. C. (1963). Longterm isolation stress in rats. Science, 142, 507.

Hole, G. J., Einon, D. F., \& Plotkin, H. C. (1986). The role of social experience in the development of sexual competence in Rattus norvegicus. Behavioural Processes, 12, 187-202.

HopP, S. L., TIMBERLAKE, W. (1983). Odor cue determinants of urine marking in male rats (Rattus norvegicus). Behavioral \& Neural Biology, 37, 162-172

HoYenGA, K. T., LeKan, R. K. (1970). The effect of rearing condition on dominance and emotionality in rats. Bulletin of the Psychonomic Society, 20, 56.

IRWIN, F. W. (1958). An analysis of the concepts of discrimination and preference. American Joumal of Psychology, 71, 152-163.

JoHNSON, R. P. (1973). Scent marking in mammals. Animal Behaviour, 21, 521-535

Juraska, J. M., Henderson, C., \& Müller, J. (1984). Differential rearing experience, gender, and radial maze performance. Developmental Psychobiology, 17, 209-215.

LABOV, J. B., WYSOCKI, C. J. (1989). Vomeronasal organ and social factors affect urine marking by male mice. Physiology \& Behavior, 45, 443-447.

LARSSON, K. (1971). Impaired mating performances in male rats after anosmia induced peripherally or centrally. Brain, Behavior \& Evolution, 4, 463-471.

Latané, B., Nesbitt, P., Eckman, J., \& Rodin, J. (1972). Long- and short-term social deprivation and sociability in rats. Journal of Comparative \& Physiological Psychology, 81, 69-75.

LeE, S., Mitchell, J., Adams, D. B. (1984). An empirical study of the structure of the patrol/marking motivational system of the rat. Physiology \& Behavior, 32, 565-573.

LYDELL, K., DotY, R. L. (1972). Male rat odor preferences for female urine as a function of sexual experience, urine age, and urine source. Hormones \& Behavior, 3, 205-212.

MATоchIK, J. A. (1988). Role of the main olfactory system in recognition between individual spiny mice. Physiology \& Behavior, 42, 217-222.

Nyby, J., Whitney, G., Schmitz, S., \& Dizinno, G. (1978). Postpubertal experience establishes signal value of mammalian sex odor. Behavioral Biology, 22, 545-552.

OEHLER, J., JÄHKEL, M., SCHMIDT, J. (1987). Neuronal transmitter sensitivity after social isolation in rats. Physiology \& Behavior, 41, 187-191.

O'Shea, L., SaAri, M., Pappas, B. A., Ings, R., Stange, K. (1983) Neonatal 6-hydroxydopamine attenuates the neural and behavioral effects of enriched rearing in the rat. European Joumal of Pharmacology, 92, 43-47.

Pappas, B. A., SaAri, M., Smythe, J., Murtha, S., Stange, K., * INGS, R. (1987). Forebrain norepinephrine and neurobehavioral plasticity: Neonatal 6-hydroxydopamine eliminates enrichedimpoverished experience effects on maze performance. Pharmacology, Biochemistry \& Behavior, 27, 153-158.

Price, E. O. (1975). Hormonal control of urine-marking in wild and domestic Norway rats. Hormones \& Behavior, 6, 393-396.

RODGER, R. S. (1974). Multiple contrasts, factors, error rate and power. British Joumal of Mathematical \& Statistical Psychology, 27, 179-198.

RODGER, R. S. (1975). The number of non-zero, post hoc contrasts from Anova and error rate I. British Joumal of Mathematical \& Statistical Psychology, 28, 71-78.

Schenk, S., Brtt, M. D., Atalay, J., Charleson, S. (1982). Isolation rearing decreases opiate receptor binding in rat brain. Pharmacology, Biochemistry \& Behavior, 16, 841-842.

SloAn, L. R., \& LATANÉ, B. (1974). Social deprivation and stimulus 
satiation in the albino rat. Journal of Comparative \& Physiological Psychology, 87, 1148-1156.

Stern, J. J. (1970). Responses of male rats to sex odors. Physiology \& Behavior, 5, 519-524.

Sullivan, R. M., Wilson, D. A., \& Leon, M. (1989). Associative processes in early olfactory preference acquisition: Neural and behavioral consequences. Psychobiology, 17, 29-33.

ThOR, D. H. (1979). Olfactory perception and inclusive fitness. Physiological Psychology, 3, 303-306.

ThOR, D. H. (1980). Isolation and copulatory behavior of the male laboratory rat. Physiology \& Behavior, 25, 63-67.

Thor, D. H., \& Flannelly, K. J. (1977a). Peripheral anosmia and social investigatory behavior of the male rat. Behavioral Biology, 20 , 128-134.

ThOR, D. H., \& FlanNelly, K. J. (1977b). Social-olfactory experience and initiation of copulation in the virgin male rat. Physiology \& Behavior, 19, 411-417.

ThOR, D. H., \& Flannelly, K. J. (1978). Sex eliciting behavior of the female rat: Discrimination of receptivity by anosmic and intact males. Behavioral Biology, 23, 326-340.

Thor, D. H., \& Holloway, W. R. (1982). Social memory of the male laboratory rat. Journal of Comparative \& Physiological Psychology, 96, 1000-1006.

Uyeno, E. T., \& White, M. (1967). Social isolation and dominance behavior. Journal of Comparative \& Physiological Psychology, 63, 157-159.

VAlzelli, L. (1973). The "isolation syndrome" in mice. Psychopharmacologia, 31, 305-320.

WARD, I. L., \& Gerall, A. A. (1968). Dominance behavior in socially isolated rats. Psychonomic Science, 13, 39-40.

Wilhelmsson, M., \& LaRsson, K. (1973). The development of sexual behavior in anosmic male rats reared under various social conditions. Physiology \& Behavior, 11, 227-232.

(Manuscript received August 6, 1990;

revision accepted for publication November 6, 1990.) 